\title{
Novel Silica Nanotubes Using a Library of Carbohydrate Gel Assemblies as Templates for Sol-Gel Transcription in Binary Systems
}

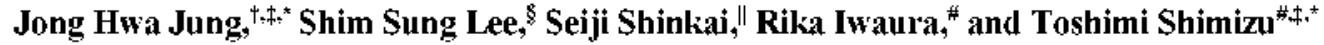 \\ ${ }^{\dagger}$ Nano Material Team, Korea Basic Science Institute (KBSI), 52 Yeoeun-dong, Yusung-gu, Daejeon 305-333, Korea \\ ¿CREST, Japan Science and Technologv Corporation (JST), Nanoarchitectonics Research Center (AARC), National Institute of \\ Adwanced Industrial Science and Technologv (-AIST), Tsukuba Central t, 1-1-1 Higashi, Tsukuba, Ibaraki 305-8562, Japan \\ ${ }^{\$}$ Department of Chemistry and Research Institute of Natural Science, Gyeongsang Kational Lniversity, Chinju 660-701, Korea \\ "Department of Chemistry and Biochemistry, Graduate School of Engineering, Kutshu Lniversity, Fukuoka 812-8581, Japan \\ * Nanoarchitectonics Research Center (NARC), National Institute of Athanced Industrial Science and \\ Technologv (AIST), Tsthituba Central 5, 1-1-1 Higashi, Tsukuba, Ibaraki 305-8565, Japan \\ Received August 27, 2003
}

\begin{abstract}
Sugar-based gelator $p$-dodecanoyl-aminophenyl- $\beta$-D-aldopy ranosides (1-3) have been shown to self-assemble in the presence of $p$-aminopheny'l aldopyranosides. The hydrogel $1+4$ showed the double-helical structure with 3-25 $\mathrm{nm}$ outer diameters. which is quite different from that of $\mathbf{1}$. The gel $\mathbf{2}+\mathbf{5}$ revealed twisted ribbon stnucture with $30-50 \mathrm{~nm}$ in widths and a few micrometers of length whereas the gel $3+4$ revealed the single and the bundled fiber stnictures. The difference in these gel supramolecular structures has successfully been transcribed into silica stnictures by sol-gel polymerization of tetraethoxy silane (TEOS), resulting in the doublehelical, the twisted-ribbon the single and the multiple (lotus-shaped) hollow fiber structures. These results indicate that novel silica structures can be created by transcription of various superstructures formed in binary gels through the hydrogen-bonding interaction. and the amino group of the p-aminophenyl aldopyranosides acts as an efficient driving force to create novel silica nanotubes. Furthermore. electron energy-loss spectroscopy (ELLS) provided strong evidence for the inner hollow structure of the double-helical silica nanotube. This is a novel and successful example that a variety of new silica stnuctures can be created using a library of carbohydrate gel fibers as their templates.
\end{abstract}

Key Words : Double-helical. Gelator. Nanotube. Silica, Sol-gel transcription

\section{Introduction}

The direct șynthesis of discrete inorganic architectures generally necessitates the use of dispersed organic supramolecular structures with commensurate size and dimensionality. Inorganic materials with well-defined three-dimensional morphologies have been synthesized using organic templates like block copolymer lyotropic mesophases. ${ }^{\text {.a }}$

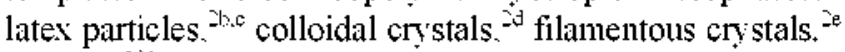
gelators. $^{2-t h}$ and they have potential applications as e.g. catalysis chromatography adsorbent or controlled release materials.

Our current research purpose is to utilize the superstructural aggregates constructed in the gel systems as templates for sol-gel polymerization. The gelators can be classified into two categories according to the driving force for molecular aggregation: nonhydrogen-bond-based gelators and hydrogen-bond-gelators. Typical examples of the former are cholesterol derivatives. ${ }^{3}$ Typical examples of the latter are amide- thoc.d urea-based cyclohexanediamines ${ }^{40}$ and sugarbased gelators. ${ }^{4 \ddagger}$ Especially. cholesterol-based organogel templates have created various hollow silica fibers with linear ${ }^{\text {s.b }}$ helical ${ }^{5.0}$ and multi-layered structures ${ }^{\text {sde }}$ by sol-gel

\footnotetext{
Co-Corresponding Authors. e-mail: jonghwagkbsi.re.kr (J. H.
} Jung), shmz-shinizuàaist.go.jp (T. Shimizu) polymerization. The findings indicate that the cholesterolbased organogel fibers act as an efficient template to create an inside tube in the polymerization process. It is already known that either the cationic charge or the efficient hydrogen-bonding site is indispensable to the sol-gel transcription in order to adsorb 'anionic' silica particles onto the organic molecular assemblies. ${ }^{5.6}$

Meanwhile. the sugar-based gelators provide various. morphologically-novel superstructures such as linear? helical. ${ }^{7.8}$ bundled. ${ }^{8 \mathrm{a}}$ multi-layered cigar-like ${ }^{8 \mathrm{~h}}$ and vesicular ${ }^{8 \mathrm{~b}}$ structures according to their self-assembling manner in the gel phase. Despite their stnuctural variety their transcription into inorganic materials has been a few achieved ${ }^{\text {fit-c }}$ The reasons for this are threefold: (i) either the presence of cationic charges or efficient hydrogen-bond donating moieties are required in order to adsorb "anionic" inorganic precursor moieties onto the organic molecular assemblies. (ii) the selfassembled morphology of organic molecules should be stably maintained during the sol-gel reaction, and (iii) the gelator should gelate protic solvents for efficient sol-gel polymerization. such as water or alcoholic solvents. However. the novel structures that satisfy the above requirements can be accomplished using stable. artificial. organic. supramolecular self-assembled structures. We have prepared sugar-based gelators 1-3 as templates. which. together with $p$-aminophenyl aldopyranosides 4 and 5 . can form gels 


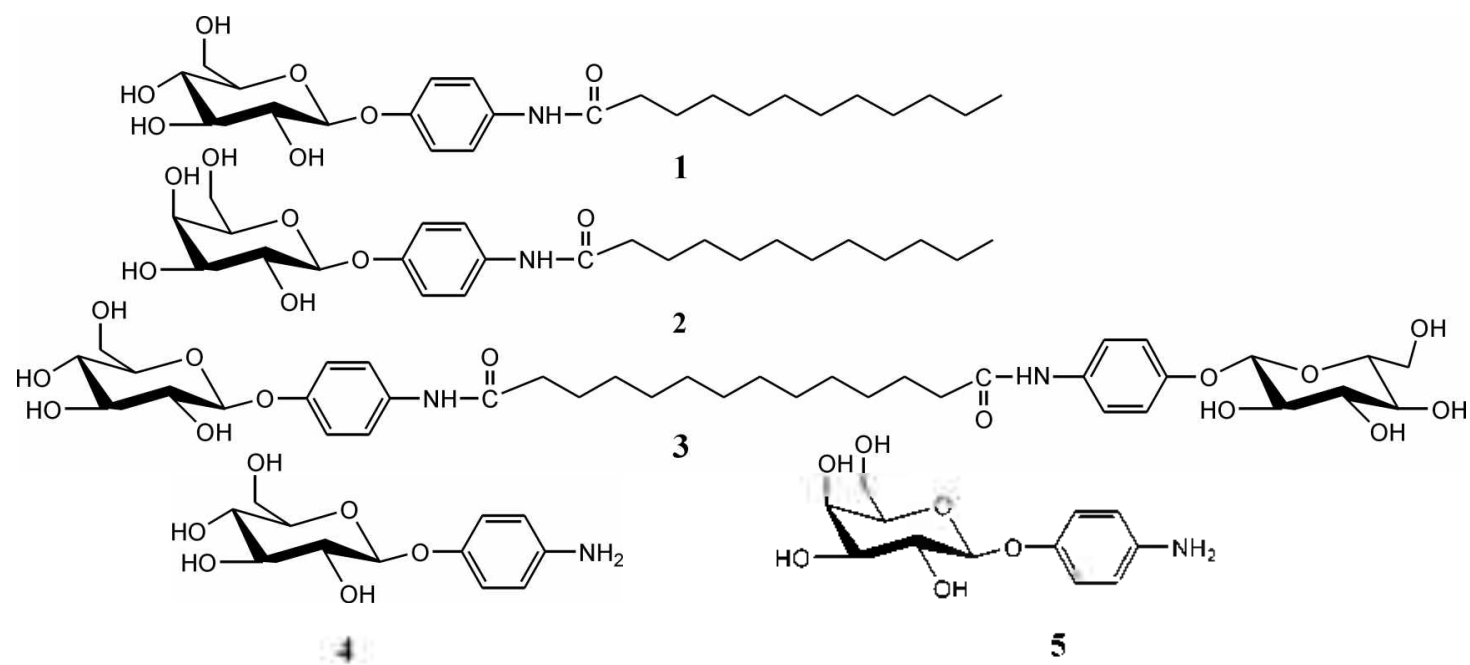

consisting of double-helical, twisted-ribbon. single and bundled fibers that can be transcribed into various silica nanotubes. Here. we report on the preparation of the selfassembled organic double-helical. twisted-ribbon, single and bundled superstructures. and their sol-gel transcription to prepare the various structures of the silica nanotubes.

\section{Experimental Section}

Equipments. ${ }^{1} \mathrm{H}$ and ${ }^{13} \mathrm{C}$ NMR spectra were measured on a Bruker ARX 300 apparatus. IR spectra were obtained in $\mathrm{KBr}$ pellets using a Shintadzu FT-IR 8100 spectrometer, MS spectra were obtained by Hitachi M-250 mass spectrometer.

TEM and SEM measurements. For energy filtration transmission electron microscopy (EF-TEM) a piece of the gel was placed on a carbon-coating copper grid (400 mesh) and removed after one nin. leaving some small patches of the gel on the grid. They were dried for $l \mathrm{~h}$ at low pressure. The specimens were examined with carl-ziess. using accelerating voltage of $120 \mathrm{kV}$ and a $16 \mathrm{~mm}$ working distance. Field emission scanning electron microscope (FESEM) was taken on Hitachi S-4500. The silica was coated with palladium-platinum and observed by $5-15 \mathrm{kV}$ of the accelerating voltage and $10 \mu \mathrm{A}$ of the enission current.

Sol-gel polymerization of TEOS. In ty'pical preparation. $(1.0-5.0) \times 10^{-\hat{3}} \mathrm{M}$ gelator and additive + or $5(3.0-12.0 \mathrm{mg})$ were dissolved in water-methanol $(10: 1 \mathrm{v} / \mathrm{v})$ or acetic acid. The organogel sample was added to TEOS $(20.0-50.0 \mathrm{mg}) /$ benzylamine $(6.0-10.0 \mathrm{mg})$ or TEOS (20.0-50.0 mg)/water $(6.0-10.0 \mathrm{mg})$ and warmed until a transparent solution obtained. Then the reaction mixture was placed at room temperature for 7-10 dayss. Subsequently. the product was dried by a vacuum pump at room temperature. Finally the gelator was removed by calcination at $200^{\circ} \mathrm{C}$ for $2 \mathrm{~h} .500^{\circ} \mathrm{C}$ for $2 \mathrm{~h}$ under a nitrogen atmosphere. and $500^{\circ} \mathrm{C}$ for $+\mathrm{h}$ under aerobic conditions

\section{Results and Discussion}

Gelation ability and SEM observations of xerogels in the presence of $p$-aminophenyl aldopyranosides. Compounds 1-3 were synthesized according to the method reported previously..$^{9}$ The products were identified by ${ }^{1} \mathrm{H}$ NMR, IR and MS spectral evidence and elemental analyses. The gelators 1-3 were able to gelate the organic solvents tested. such as chloroform. tetrahydrofuran, l-butanol. 1-hexanol and ethylacetate. Of particular interest is its ability to gelate water in the presence of methanol or ethanol ( $c a .1-50 \mathrm{wt} \%$ ) at concentrations less than $0.1 \mathrm{w} t \%$. corresponding to more than 50000 molecules of water per gelator molecule. ${ }^{9}$ These results prove that 1-3 can act as an amphiphilic gelator both in water and organic solvents.

However. we have found that the presence of at least a moderate amount of cationic charges or efficient hydrogenbinding sites in the gel architecture is indispensable for solgel transcription into inorganic materials. ${ }^{56}$ Therefore. we studied a binary gel system to use the template of the sol-gel transcription in the presence of $p$-aminophenyl aldopyanosides 4 and 5 , the amine moiety of which can function as a binding site for hydrolyzed tetraethoxysilane (TEOS). The gelation ability of these gelators 1-3 in the presence of $p$ aminophenyl aldopyranosides ( 4 and 5 ) was estimated in water and acetic acid. They can gelate in the presence of 4 and/or 5. According to differential scanning calorimetry (DSC) study, an endothernic sol-gel phase transition temperature of 1 gradually increased from 90 to $110^{\circ} \mathrm{C}$ by addition of $p$-aminophenyl aldopyranosides. indicating that $p$-aminophenyl aldopyranoside $\mathbf{4}$ or $\mathbf{5}$ was truly incorporated into the gel phase of 1,2 or 3 .

We observed the xerogel structures prepared from their gels (hydrogel or acetic acid gel) to obtain visual insights into the aggregation mode by SEM. The hydrogel 1 in the presence of 4 shows well-defined double-helical fiber structure with diameters of 3-25 nm (in Fig. la). lengths of several micrometers. The gel of 1, on the other hand only displayed a somewhat twisted fiber structure with diameters of $20-100 \mathrm{~nm} .{ }^{9}$ These results suggest that the self-assembled superstructure in the gel of $1+4$ was orientated into a more explicit chiral packing through the intermolecular hydrogenbonding interactions of the sugar moieties as well as the $\pi-\pi$ 


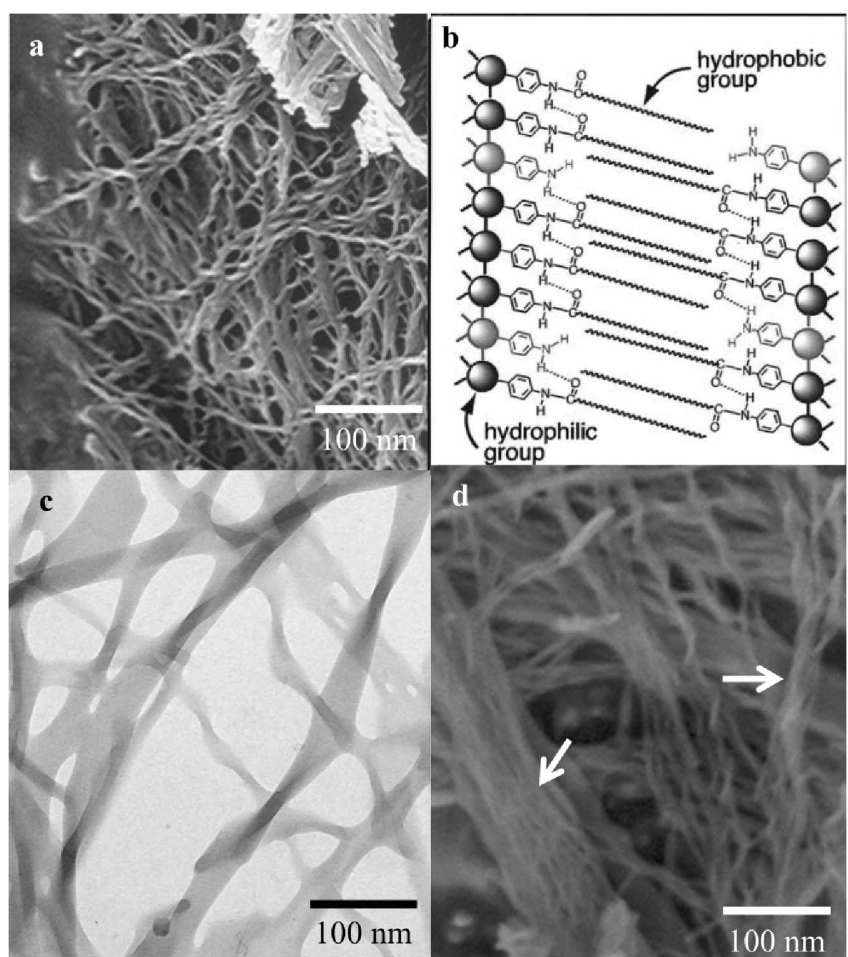

Figure 1. (a) FE-SEM image of the xerogel prepared from the mixed gel of 1 and $4(1: 4=1: 1 \mathrm{w} / \mathrm{w})$ in water-methanol (10:1 viv). (b) A possible self-assembling model in the bilayered chiral liber from the mixed gel of 1 and 4 . EF-TEM images of the xerogel prepared from the mixed gel of (c) 2 and $5(2: 5=1: 1 \mathrm{w} / \mathrm{w})$ and (d) 3 and $4(3: 4=1:$ I $w / w)$

stacking of the phenyl moictics present in both $\mathbf{1}$ and $\mathbf{4}$ as shown in Figure $1 \mathrm{~b}$. According to NMR experiment, 20\% of $p$-aminophenylglucopyranoside 4 in a $1: 1$ mixture was incorporated into gel fiber. 'lo further sludy the chiral packing structure, we measured circular dichroism (CD) spectra of the gel 1 , which gave a $C D$ maximum at $230 \mathrm{~nm}$. Addition of $\mathbf{4}$ to the gel of $\mathbf{1}$ resulted in a gradual increase in the CD intensity, proving that the microscopic chiral change upon going from the pure gel of $\mathbf{1}$ to the mixed gel can be reflected in the resultant macroscopic chiral structure.

the gel 2 in the presence of 5 displays a partly twisted ribbon structure with 70-100 $\mathrm{mm}$ widths and several micrometer length (Fig. 1c), which is similar to that observed for $\mathbf{2}$ in the absence of $\mathbf{5}$ whereas acetic acid get 3 in the presence of $\mathbf{4}$ displays the straight and large fiber

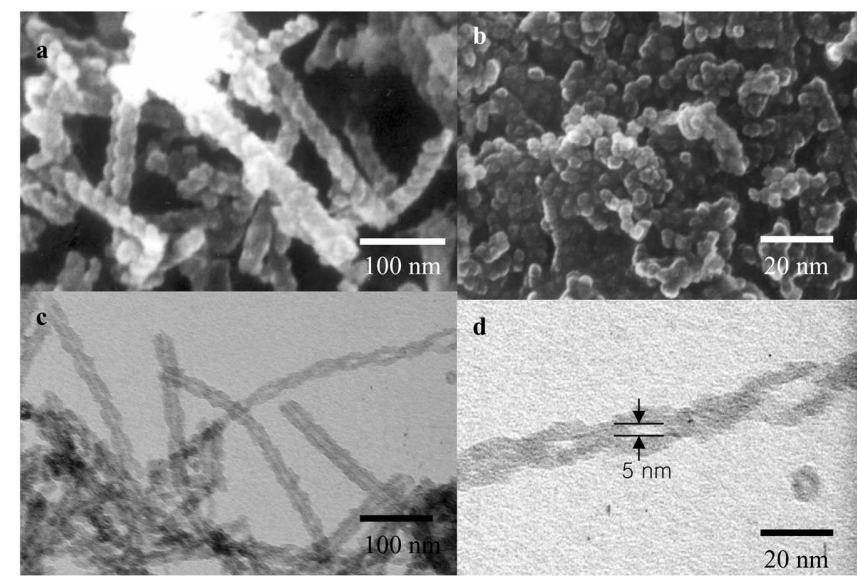

Figure 2. FE-SEM image of the silica nanotubes obtained from 1 and $4[$ (a) $1: 4=I: I w / w$ and (b) $\mathbf{1}: 4=9: 1 \mathrm{w} / \mathrm{w}]$ and (c and e) EF-TEM imase of the silica nanotubes obtained from $1+4=1:$ ] wiw).

structure with 10-50 nm diameters (Fig. 1d: arrows indicate the bundled fiber). It should be emphasized here that one can recognize many stripes in a gigantic organogel fiber in high magnification observation. These results indicate that the sugar-integrated gel systems can act as templates to create various new silica structures.

Sol-gel polymerization towards transcription of the self-assembled structures using binary systems. To transcribe the double helical supersiructures of the hydrogels into their analogous silica structures, we carricd out the solgel polymerization of TEOS in a water-methanol $(10: 1 \mathrm{v} / \mathrm{v})$ gel of 1-3 in the presence of 4 and/or 5 . The structure of silica nanotube obtained from $\mathbf{1 + 4}$ was observed by $\mathrm{S} \Gamma \mathrm{M}$ and energy filtration transmission electron microscopy (EFTFM). After calcination. the morphology of the silica product turned out to be the well defined double-helical nanotube possessing a diameters of $50-80 \mathrm{~nm}$ and a pitch of 50-60 $\mathrm{nm}$ (Fig. 2a). These results prove that the double helical structure of the self-assembled gel fibers of $\mathbf{1}$ and $\mathbf{4}$ was successfully transcribed into the silica nanotube structure. most likely through hydrogen-bonding interactions between the amine moiety of $\mathbf{4}$ and negatively charged oligomeric silica particles. Additional investigation showed that transcription of mixtures of $\mathbf{1}$ and $\mathbf{4}$ with weight ratios $\mathrm{R}[-\mathbf{4} /(\mathbf{1}+\mathbf{4})]$ belween 0.2 and 0.8 , at all times the right-handed double helical silica was obtained (Table 1).

Table 1. Results and conditions for the sol-gel polymerization

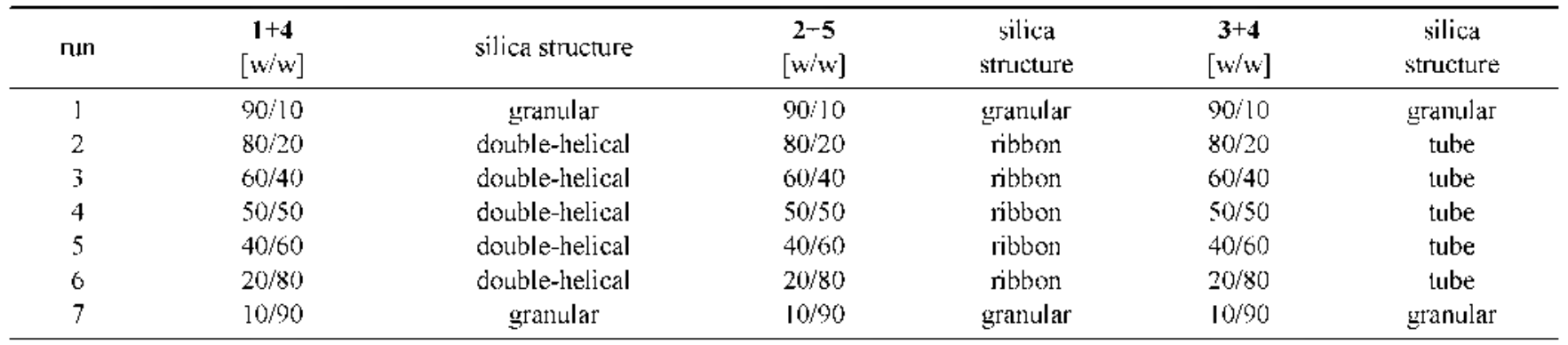




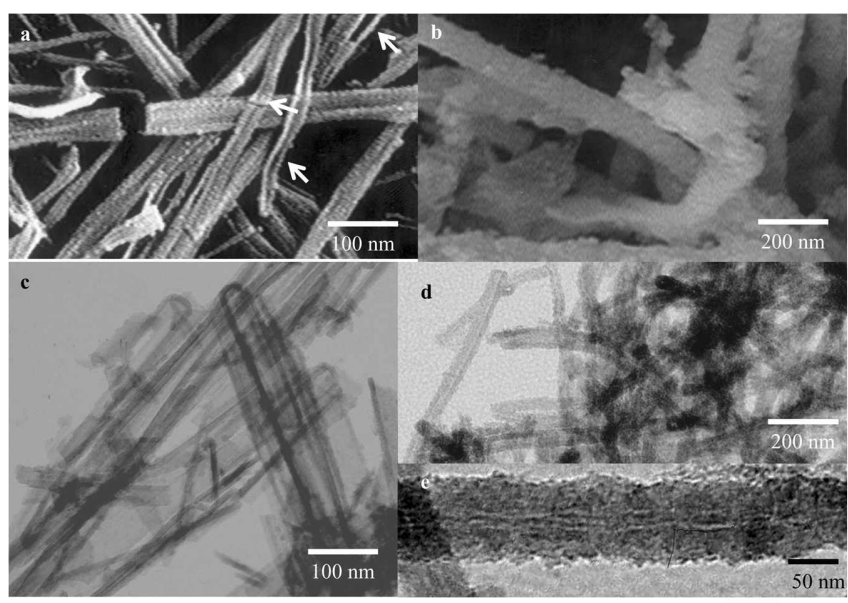

Figure 3. FE-SEM images of the silica nanotube obtained from the mixed gel of (a) 2-5 and (b) $3+4$ ( 1 : 1 w/w) after calcinations. EFTFM images of the silica nanotubes (c) $2+5$ and (d and e) 314 (1: I wiw) alter calcinations

For R-values below 0.2 , the resultant silica only displayed the comventional gramular structure (Fig. 2b). The results clearly support the vicw that (i) the presence of a minimal number of the hydrogen-binding sites is indispensable for transcription of the self-assembled structure into silica struclure, (ii) the helicity of silica can be accuratcly transcribed from that of the template, and (iii) this method will be applicable for the efficient transcription of selfassembled superstructures into inorganic materials.

TI:M pictures were taken after calcination of the transcribe hydrogels (Fig. 2c) in order to further confion whether the self-assembled supersiructure really acted as a template for the fornation of the silica structure. The silica struclure obtained from the mixed gel of $\mathbf{1 + 4}$ in water-methanol shows an inner hollow structure originating from the helical gel fibers. High magnification TLM images of the doublehelical silica tubes display approximately 5.0-1m nanospace belween the helical strands (Fig. 2d). Furihermore, there is almost no change between the silica before and after calcination, indicating that the double-helical structure of the silica inded originates from the self-assembled organogel superstructure. The hollow structure of the double-helical silica nanotube will be explained in detail by ELLS technique later. On the other land, the resultant obtained from the hydrogel $\mathbf{1}$ in the presence of $\mathbf{5}$ showed the granular structure even though 1 gelated water in the presence of additive 5 , indicating that $p$-aminophenyl galactopyranoside $\mathbf{5}$ is not efficiently incorporated into the glucose-type gel fiber structure.

Figures $3 \mathrm{a}$ and $3 \mathrm{~b}$ illustrate SГM pictures of the silica materials obtained from aqueous gel $\mathbf{2 + 5}$ and acetic acid gel $\mathbf{3}+\mathbf{4}$ by sol-gel polymerization. The silica obtained from hydrogel $2+5$ showed the lwisted-ribbon structure with $70-$ $100 \mathrm{~mm}$ width. They accidentally catch several broken nanotubes (arrows in Fig. 3a). It is seen from these pictures that these particles have the hollow structure. Presumably, this breakage is induced during calcination to remove organic template. In contrast, the silica obtained from acetic acid gel 3+4 shows the liber struclure with $70-120 \mathrm{~nm}$ outer diameters (Fig. 3b). Furthermore, TL.M pictures of these silica materials are displayed in Figures $3 c, 3 \mathrm{~d}$ and $3 \mathrm{e}$. The silica material obtained from $\mathbf{2}-\mathbf{5}$ shows the twisted-ribbon structure with $50-80 \mathrm{~nm}$ inner widths and $10 \mathrm{~nm}$ wall thickness after calcinations (Fig. 3c). This result indicates that the sugar-integrated gel systems can act as templates to create various new silica structures. More interesting is the silica nanotube obtained from $\mathbf{3}+\mathbf{4}$. The silica nanotube
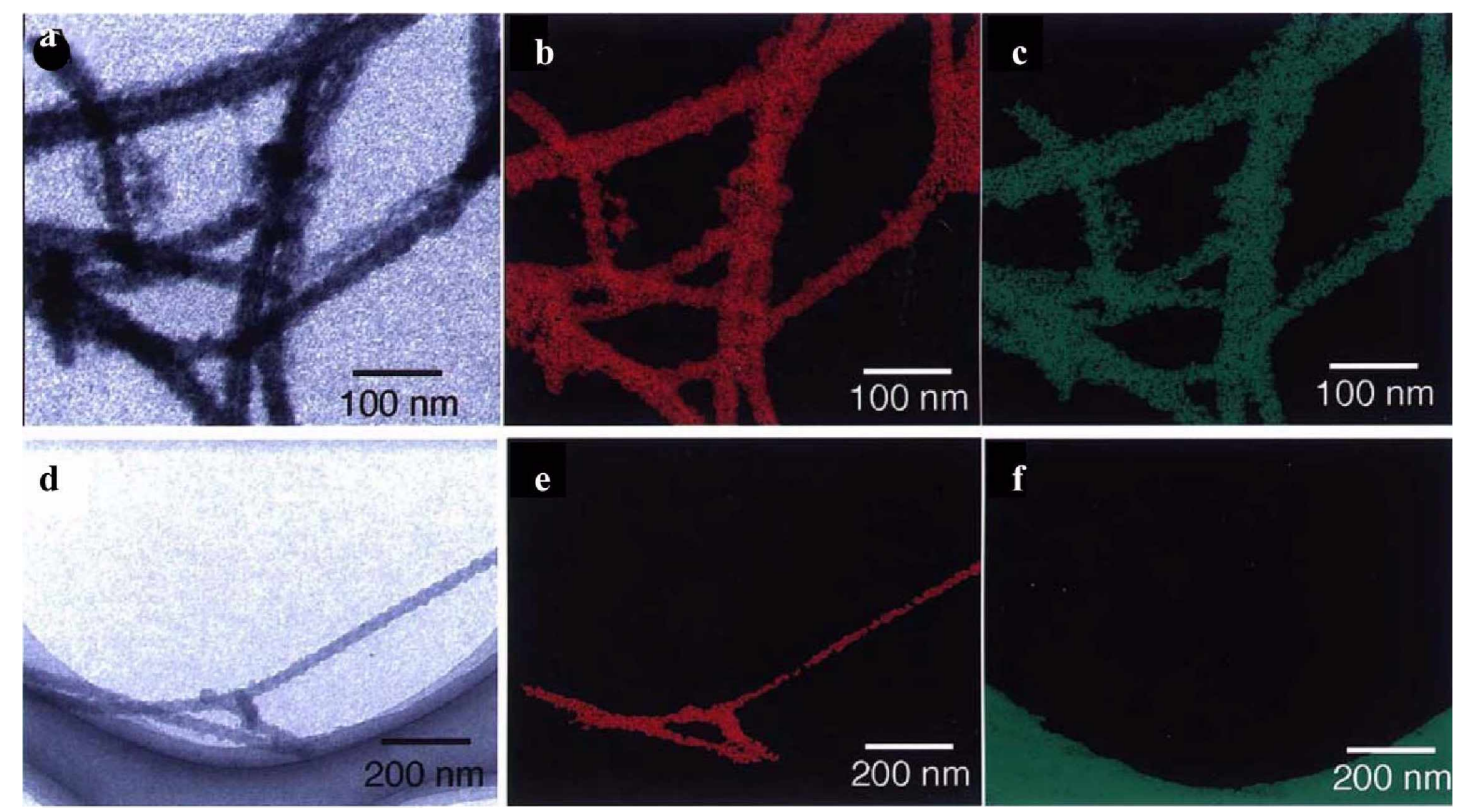

Figure 4. TEM images with electron energy-loss spectroscopy (EELS) of the double-helical silica nanotube obtained from the mixed gel of 1 and $2(1: 1$ wiw). (a) zero-loss image (b) silicon component and (c) carbon component before calcination. (d) zero-loss image, (e) silicon component and (1) carbon component alter calcination 
(i)
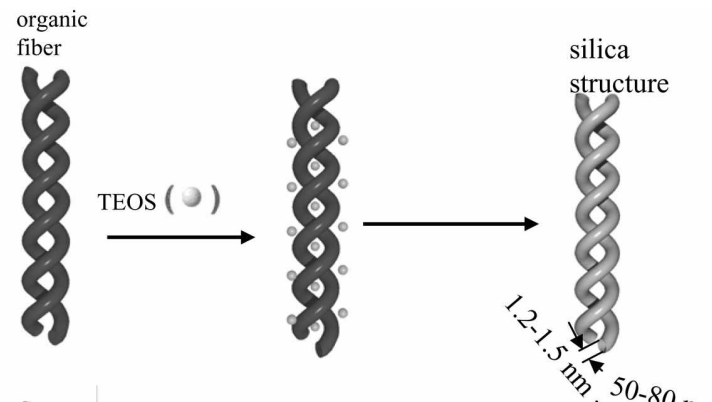

(ii)

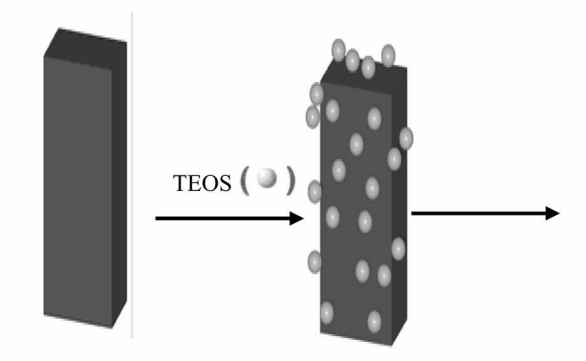

(iii)
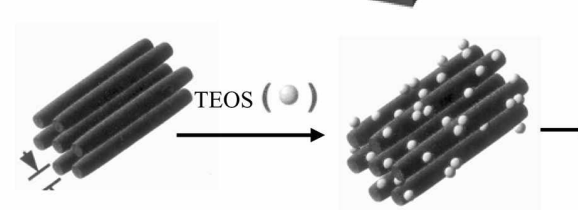

(iv)

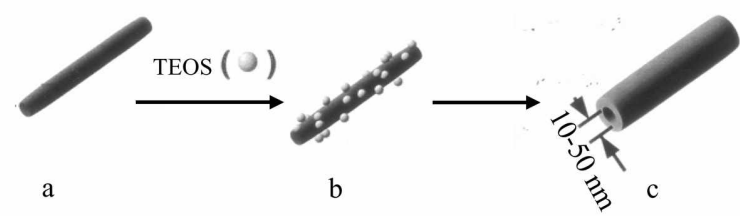

Figure 5. Schematic representation for the creation of various silica structures from the organogel state of 1 (i), 2 (ii) and 3 (iii and iv) by sol-gel polymerization: (a) gelators; (b) sol-gel polymerization of TEOS and adsorption onto the gelators and (c) double-helıcal structure (i), ribbon structure (ii), single and lotus-like structure (iii and iv) of the silica materials formed after calcination (SEM and TFM pictures in Figs. 1, 2 and 3 were taken at this stage)

reveals two different morphologies. The first is the single

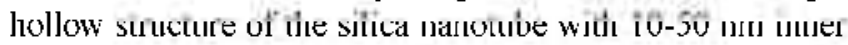
diameters (liig. 3d). The sccond one is lotus-type silica nanotube with ca. $5 \mathrm{~nm}$ inner diameter (Fig. 3e). Probably, the two different morphologies of the silica nanotubes are induced in the mixture of the single- and the bundled gel fiber structures.

Since electron energy-loss spectroscopy (ELLS) is capable of providing clemental and chemical information at high spatial resolution, some energy filters equipped on the TCM have developed. Therefore, the functioning of the gel tibers as a tcmplatc for sol-gel transcription was conlinmed independently by elemental mapping with electron energyloss spectroscopy ${ }^{\prime \prime \prime}$ as shown in Figure 4. The material (Fig. 4a) contains silicon (Fig. 4b) and carbon (Fig. 4c) components before calcination, whereas the targeting material (Fig. 4d) exclusively slowed silicon component (Fig. 4e) after calcination. This result implies again that TГOS was adsorbed on the surface of organic double-helical fibers as a result of hydrogen-bonding interactions. Furthemnore, all results obtained clearly supports the vicw that the double-liclical silica nanotube possesses a nanometer-sized cavity.
As a sumnary of the foregoing observations, we now propose the mechanism for the formation of the novel double-helical silica structure obtained from hydrogel 1 (Fig. $5 ;$ i), the twisted ribbon fiber silica structure obtained from hydrogel 2 (Fig. 5: ii) and the single and lotus-type silica obtained from acetic acid gel 3 (Fig. 5: iii and iv). Oligomeric silica species are adsorbed onto the surface of the bundled fibrous structure of $\mathbf{3}$ and the polymerization further proceeds along these bundled fibrils. This propagation mode eventually yiclds the lotus-type with several small hollow cavities and single silica with one large hollow cavity after combustion of gelators by calcination ( $\Gamma i g .5 \mathrm{c}$; iii and iv). In contrast, 1 and 2 provide the minute fibrous structure, respectively. Then, the tubular silica grows up by sol-gel polymerization along these surfaces (Figs. 5b and $5 \mathrm{c}$ ). As supporled by correlation between the xerogel structures (Fig. i) and the resultant silica gel structures (Figs. 2 and 3 ), the sugar-integrated gel structures are directly and scrupulously transcribed into the silica structures utilizing the lydrogen-bonding interactions in binary gel system.

\section{Conclusion}

The presenl paper has demonstrated that a varicty of superstructures are conveniently obtained using selfassembling of sugar-integrated organogel and hydrogel. Thus, a varicty of supcrsiructural silica materials such as double-helical, twisted-ribbon, single fiber and lous-like structures are created by a template method with the aid of the hydrogen-bonding interation of the oligomeric silica species in the binary gel systems. The amino group of added p-aminophenyl aldopyranosides in gel fiber acted as the efficient driving force to produce novel struclutes of the silica nanotubes. We believe, therefore, that the present system is useful for transcription of various self-assembled superstructures into silica matcrials which ate cventually applicable to catalysts, memory storage, ceramic filters, etc.

\section{References}

1. (a) Mann, S. Biomimenic Moterials (hemistry: Mann, S., Ed: VCH: New York, 1996. (b) Yang, H.; Coombs, N.; Orit, G. A. Nante 1997, 386, 692. (c) Jehrens, P.; Stucky, G. D. Angert: (Wom. Int. lid Ingt 1993, 32, 696. (d) Miyaji, F.; Davis, S. A. Charmant, J. P. H: Mann, S. ('hem. Mater: 1999, /l, 302I. (c) Ozis, G. A. (hem. ("ommun. 2000) 419).

2. (a) Zhao, D.; Feng, J.: Huo, Q; Melosh, N.: Fredrickson, G. H. Science 1998, 279, 548. (b) Caruso, F.; Lischtenfeld, H.; Giersin, M.: Mohwald, H. I. Am. ( $h e m$. Sox 1998, /20, 8523. (c) Fujikawa. S: Kunitake, T. (Wem. Ist 2002, I134. (d) Velev, O; Jede, T. A. Lobo, R. F.; Lehnoff, A. M. (hem. Mak') 1998, 0 , 3597. (e) Miyaji, F.; Davis. S. A.: Charmant, J. P. H: Mann, S. (Them. Mater: 1998, 10, 3597. (1) Ono, Y: Nakashima, K.; Sano, Mi; Kanekiyo, Y.: Inoue, K.: Hojo, J.: Shinkai, S. (hem. (ommmm. 1998. 1477. (g) Ono. Y: Kanekiyo, Y; Inoue, $\mathrm{K}$ : Iojo, J. Shinkai, S. ( / tom. Istt. 1999, 23. (h) Kobayashi, S.: IJamasaki. $\mathrm{V}$ : Suzuki, M.: Kimura, M.; Shirai. I1: Ilanabusa, K. I. Am. (hem. Sж: 2002, 122, 5008 .

3. (a) Murata, K.; Aoki, M.; Suzuki, I:; Harada, T.: Kawabata, H.: 
Komori. T: Ohseto. F.: Ueda. K.: Shinkai. S. J. Am. Chem. Soc. 1994. 116. 6664 and references cited therein. (b) James. T. D: Murata. K.: Harada. T.: Ueda. K.: Shinkai. S. Chent. Lett. 1994. 273. (c) Jeong, S. W.: Murata, K. Shinkai, S. Stpramol Si. 1996. 3. 83. (d) Slunkai, S.: Murata. K. J. Mater. Chem. tFeature Article) 1998. 8, 485. (e) Wang. R.: Geiger. C: Chen. L: Swanson. B.: Whitten. D. G. J. Am. Chem. Soc. 2000. 122. 2399. (t) Duncan. D. C.: Whitten. D. G. Langmit 2000. 16. 64t5. (g) For recent comprehensive reviews. see Terech. P: Weiss. R. G. Chem. Rev: 1997. 97. 3313. (h) Kawano. S.-I: Fujita. N.: Bommel. K. J. C.: Shinkai, S. Chem. Lett. 2003. 12

4. (a) Hanabusa. K: Yamada. M.: Kimura, M.: Shirai. H. Angew: Chem. Int. Ed. Engl. 1996. 35. 1949 (b) de Loos. M.: van Esch. J.: Stokroos. I.: Kellogg. R. M.: Feringa. B. L. J. Am. Chem. Soc. 1997. 119. 12675. (c) Schoonbeek. F. S.: Esch. J. H.: Hulst. R.: Kellogg. R. M.: Feringa, B. L. Chem. Em, J. 2000, 6. 2633. (d) Nakashima, T.: Kimizuka. N. Adn. Mater. 2002. 1t. 1113 . (e) Esch, J. H.: Feringa, B. L. Angew. Chem. Int. Ed. Engl. 2000, 39. 2263. (f) Yoza. K.: Amanokura. N.: Ono. Y.: Akao. T.: Shinmori. H.: Takeuchi. M.: Shinkai, S.: Reinhout. D. L. Chem. Eur. J. 1999. 5.2722 .

5. (a) Nakamura. H.: Matsui. Y. J. Am. Chem. Soc. 1995, 117, 2651. (b) Ono, Y.: Nakashinna. K.: Sano. M.: Kanekiyo, Y.: Inoule. K.: Hojo, J.: Shinkai, S. Chem. Commm. 1998. 1477. (c) Jung. I. H.;
Ono. Y.: Shinkai. S. Angew: Chem, Int. Ed. Engl. 2000. 39. 1862 (d) Jung. I. H.: On1o. Y.: Shinkai. S. Langntuir 2000. 16. 1643. (e) Jung. J. H.: On1o. Y: Shinkiai. S. J. Chent. Soc. Perkin Trons. 2 1999. 1289.

6. (a) Jung. J. H.: Ono, Y: Hanabusa, K.: Shinkai. S. J. Am. Chem Soc. 2000. 122, 50018. (b) Jung. J. H.; Amaike. M.: Shintai, S Chent Commm. 2000. 2343. (c) Jung. J. H.: Shinkai. S. J. Chent. Soc. Perkin Trans 22000.2393

7. (a) Amanokitra. N.: Kanekiyo. Y.: Shinkai. S.: Reinhoudt. D. L. $J$. Chem. Soc. Perkin Trans. 2 1999. 1995. (b) Yoza. K.: Ono, Y: Yoshihara, K; Akao, T.: Shinmori, H.; Takeuchi. M.: Shinkai. S.; Reinhoudt. D. L. Chem Commun. 1998, 907.

8. (a) Hatkamp. R. T. H.: Feiters. M. C.: Nolte. R. T. M. J. Ong Chent. 1999. 6f. 412. (b) Beginn. U.: Keinath. S.: Möller. M Macrontol Chent. Phus 1998. 199. 2379. (c) Sugivasu. K.: Tamaru, S.: Takeuchi. M.: Berthier. D.: Huc, I; Oda, R; Shinkai. S. Chem. Commun. 2002, 1212

9. (a) Jung, J. H.; Shinkai. S.; Shimizu. T. Chem. Ew: J. 2002. 8. 2684. (b) Jun1g. T. H.: John1. D.: Masuda. M.: Yoshida. K.: Shit1kai. S.: Shimizu. T. Langmuir 2001. 17.7229.

10. The EELS spectra were done with Zeiss LEO 912 OMEGA. using accelerating voltage of $120 \mathrm{kV}$ on the micro carbon grids. The elemental maps were obtained by subtracting the background intensities under core-loss edges using three-window technique. 